\title{
Research on Branded Garment Design from the Perspective of Fashion Information
}

\author{
Yixuan Guo \\ School of Business Administration, Shanghai Lixin Financial Institute, Shanghai, China
}

Keywords: Branded garment design, Fashion information, Fashion design

\begin{abstract}
Garment consumption oriented by the fashion information trend has become an essential part of the modern fashion life. Fashion information and garment design have the same characteristics of business, timeliness and group. Based on the above analysis, this paper gives the fashion design, brand development and brand operation method based on fashion information to provide some references for the relevant researchers.
\end{abstract}

\section{Introduction}

Fashion refers to a certain idea or way of life advocated by the general public for a certain period of time. It involves all fields of social life, such as basic necessities of life, emotional expression or mode of thinking, and so on. Some people think that fashion is an alternative and maverick. Actually, fashion should be a manifestation of social values, a manifestation of the mainstream art and culture, a call for social needs, and a pioneer culture. Information refers to information and information relating to certain specific things. Data include data and facts, while messages include messages and trends. The concept of information is very different from that of information. Broadly speaking, information is news, and everything that can be felt by a person can be called information. In contrast, the concept of information with certain aspects of an event or something of the targeted, in other words, the information is targeted on information filtering, sorting, analysis, and the formation of a commercial value of the message. Thus, fashion information is through a large collection of market data, to master a lot of fashion news and dynamic, and these are information filtering, sorting, analysis, explore its regularity and intrinsic value, finally reaction in the fashion to have a certain commercial value of information. A brand is a mark or symbol that can be distinguished from other similar organizations, products, or services. However, in today's highly developed market economy, the meaning of brand has expanded. The purpose of the brand is not only to distinguish, but also to become a means of gaining high profits in the market. Because of the market economy and the business operation mode of the clothing industry, the clothing design begins around the brand marketing strategy established by the enterprise, and becomes a way to set up the enterprise brand and establish the enterprise brand culture.

\section{Common Features of Fashion Information and Garment Design}

Feature of Business. Fashion is an all-encompassing concept. Its tentacles go into every aspect of life. Fashion brings people a happy mood and elegant, pure, taste and extraordinary feelings, to give people different temperament and charm, can reflect the extraordinary quality of life. Finally, fashion information needs to realize its commercial value through specific market operation. In the modern era of commodity economy, the spread of fashion information is more accomplished through the sale of its derivative commercial products. Fashion information has become the main means to stimulate purchasing behavior, because of its psychological satisfaction, the value will often exceed the material and practical value of the product itself, and become the main factors to stimulate purchasing behavior. This promoted fashion information to a greater extent and expanded its acceptance side, 
while merchants gained greater profits by incorporating goods into fashion elements. Fashion information has gradually begun to lead the direction of the third industry. As the integration of fashion information, the third industry has produced tremendous economic benefits. Japan's animation and its surrounding industries has become Japan's third industry's economic pillar. The use of fashion information is also a major manifestation of the economic growth in the United States in recent years. From the perspective of the producer, the fundamental purpose is to design and production of clothing apparel sales profit, while buyers buy clothes to have from wearing function evolution of the pursuit of life taste and beautify themselves, they find a meeting point to realize the commercial value of clothing, clothing design business is obviously the. Business means risk. No one can accurately predict how consumers evaluate new creative products. Even it has a great market sensation effect and many followers, it may also lose.

Feature of Timeliness. The timeliness of fashion information means that it will form, pop and disappear in a certain period of time. Compared with the long history of the traditional culture, it has a sense of the times and a prominent manifestation of the development of human culture. The formation, development, prosperity and decline cycle of fashion information is becoming shorter and shorter with the development of modern society. For example, a version of the film and television works by the middle-aged generation as a classic, which lasted for decades, has not changed. And now the film and television works emerge in endlessly, for young people, a classic works cannot have such a long shelf life predecessor. Especially in the clothing, clothing change cycle is increasingly shorter, as the rise of the garment tunic, flourished for decades, but the modern fashion cycle is less than a year or even less than a quarter of the speed changing. The change of timeliness of fashion information is closely related to the rapid development of human society. Increasingly fast pace of work life caused by the fashion information tends to be more and more utilitarian, old people speed constantly promote the fashion designer to launch the new cultural concept of style. Once these styles are considered no longer novel, they will be eliminated by new styles, which is the embodiment of the timeliness of clothing, which leads to the variability of clothing products. It can be said that clothing is very sensitive to the aging, once out of breath, it means that the clothing products in the market lost competitiveness. The timeliness of fashion information comes from the endless desire of people. People are always hungry for things that they want and haven't got for the time being. New fashion information is constantly replacing old fashion information, and new dress designs are constantly required to replace old clothing designs. This is the timeliness of fashion information and costume design.

Feature of Group. The group of fashion information is manifested in its acceptance and dissemination. People in different age groups, different occupations and different life backgrounds often form different social groups because of their different cultural orientations and values. When the new fashion information is produced, it will be accepted, absorbed and developed by the corresponding groups. All kinds of groups, the two groups of women and adolescents is a part of the most deeply affected by the impact of fashion information, but also to promote the backbone of fashion information development, fashion information business out now in fashion, beauty, makeup and other content of life, entertainment, film and television animation, fiction, music, shows and other content is the content of consumption of the two groups of the most loved. Fashion information influences other social groups around them by influencing them. Most of the group members who receive fashion information are well educated, have a certain economic base, and have an open mind. The elements that affect fashion information include economics, nature, technology, politics, society, culture. Economic factors not only directly determine the purchasing power of consumers, but also affect the consumption structure and consumption habits of consumers. We can clearly feel that the more backward the economy, the slower the fashion cycle. The natural environment is one of the main factors affecting consumer habits. For example, in a region with distinct seasons, the structure of the dress is usually rich and complete, and there is no season, and the dress structure is unitary. At the same time, climate, ecology and other environmental factors are also important reasons to change people's concept of life. Science and technology is an important index for the development of apparel industry. Technology will not only affect every aspect of the apparel industry, including fabric 
development, process technology, production management, marketing, etc., but also change people's living habits and so on. They are happy to share new discoveries, ideas, and responses among their peers. They often want to be different. They are not only fashion followers, but creators of fashion. The clothing design also has the community. Fashion design from the perspective of cultural orientation to a social culture or sub culture groups, because the degree of culture and cultural literacy often determines the consumer for the aesthetic taste and level of clothing, and different ethnic groups and different regions have different preferences and taboos. All these will bring certain influence to the clothing design.

\section{Branded Garment Design from the Perspective of Fashion Information}

Garment Design Based on Fashion Information. Garment design is a trivial and systematic project, and each element is interdependent and subject to each other to form a complete design. Therefore, in order to make the design more smoothly, it is necessary to follow a certain design and development process. Brand apparel product development is for a clothing brand production, consumption and creative activities, the main consumer is its design, the purpose is to sell. Therefore, in the design must be based on the popular trend, brand positioning, image style, consumer demand and other aspects of the production process as the basis, but also must follow certain product development process, to ensure that all aspects of an orderly manner. The process is to study the trend of the process of apparel design, so in the design, the full collection of market information, including the popular trend of the next quarter, the market trend analysis, the last quarter sales report is very important. Since clothing usually takes six months to one year to develop and design, it is essential to design a design concept for the next quarter. The design strategy is based on the results of the market survey and provides a reasonable strategy for the future development of the brand, including design styles, trends and quantities, color trends, fabric trends. According to the brand design strategy, draw up the specific garment effect drawing, including the drawing and modification of the garment effect drawing. After the renderings have been conceived, they can be sent to the factory for sample making. After the sample is confirmed, the stage of mass production has been beyond the scope of garment design. This garment design and development process is just a generic, common procedure.

Brand Development Based on Fashion Information. Now the competition of clothing is the competition of design style and the competition of clothing brand. In fact, people's understanding of clothing has gone through four stages, from the initial warmth to social class system, and then to the aesthetic needs. Finally, it pays attention to the cultural consumption of the brand. Therefore, the focus of competition in the apparel market is the brand. It can be said that brand is the more important and lasting asset of enterprise. Under the background of internationalization and homogenization of competition in the garment industry, the shaping and management of systematic and strategic brand is the core of establishing customer loyalty and winning market competition status. The significance of clothing brands is, first of all, that it creates additional value. High value-added is a common feature of all successful brands. However, any one brand cannot be forced to sell their own customers, but cannot rely on false means to deceive consumers, the only way is to win the consumer's attention and favor, make customers through active participation and experience to become brand advocates. Clothing brand positioning is the prelude of clothing Commodity planning, but also the core content of planning. Strictly speaking, brand positioning and market positioning, product positioning are interrelated, but the nature of the concept of different. Market positioning refers to the clothing enterprise according to its own nature, characteristics, technology, resource allocation and so on, the products and services are accurately located in a consumer group. Product positioning refers to the clothing enterprises according to the specific characteristics of target customers and consumer needs, product categories, functions, styles, prices and other attributes recognized. And brand positioning is clothing enterprise positioning through the market, in the customer led, product based principles, clothing brand image positioning. As far as the relationship between the three is concerned, market positioning is the premise of brand positioning, while product positioning is one of the contents of brand positioning. 
Brand Operation Based on Fashion Information. Garment brand operation is a complex and systematic project, including initial market research, brand positioning, brand planning and strategy implementation, and finally, each link to each other, if there is a link error, will directly affect the fate of the benefits of a brand and a clothing enterprise. Usually, consumers can fully understand the value of clothing brand through several channels, which is derived from the brand value of consumer experience. In other words, through the continuous reliability of clothing products, so that consumers have a certain degree of trust in the brand. In the branded apparel market, consumers generally reduce the risk and uncertainty of buying by choosing familiar clothing brands. Brand value derived from brand superiority belief. It refers to the clothing brand's high recognition and good evaluation, which can make the consumer form a stable brand superiority belief, this belief is enough to influence the consumer to the brand product actual function appraisal. Brand value derived from brand image. Now the most obvious is that, due to the development of science and technology, people's pace of life is more and more fast, fast-paced life not only makes people psychological impetuous, but also directly affect the fashion cycle. Political factors will directly affect the national economy, as well as the survival and development of clothing enterprises. Studies have shown that the more democratic politics, the better the order of the country, the more fashionable the trend. Social culture refers to the national characteristics, cultural traditions, values, life styles, religious beliefs, ethics, educational standards, social structures, customs, etc. of the country or region. Throughout the history of the development of clothing, it is not difficult to find that the evolution of clothing is a reflection of social and cultural development. The cultural connotations of different nationalities, religions, races and regions seriously influence people's preferences for clothes, consumer psychology and consumption habits. The establishment of brand image is now an important means of competition in the clothing market. Consumers can obtain more information from the content of the brand image, such as personality, culture, lifestyle and so on. In the process of visual and psychological perception, consumers naturally link the brand to their own lifestyle, and affect the consumer's judgment of the brand and the position of the brand in the minds of consumers. The professional fashion information company opened a new window for Chinese clothing enterprises and apparel brand development. In fact, many Chinese brand clothing enterprises with their own reality, in keeping ahead of the traditional product development model, with the rapid imitation trend of the design mode of operation, or fashion information company in cooperation with professional design, in order to reduce the prediction risk, improve product design quality, achieve customer satisfaction.

\section{Conclusion}

The combination of a clothing enterprise and a professional fashion information institution is a new opportunity for domestic clothing enterprises to develop good brand of garment. The establishment of garment brand is a systematic and long-term project. Each link in the supply chain will influence the establishment of garment brand with varying degrees. Fashion enterprises should take fashion information as the breakthrough point. The models of costume design, brand development and brand operation will become an important trend in the future.

\section{References}

[1] Liu Chengxia, Lu Pei. Basic methods of deconstruction application in fashion design [J]. Journal of Textile Research, 2011, 32(11): 96-99+105.

[2] Yang Kailang, Liu Xiaogang. New Trend of Fashion Design Based on Slow Fashion Concept [J]. Journal of Zhejiang Sci-Tech University (Natural Sciences Edition), 2014, 32(6): 489-492.

[3] Chen Chen. Minimalist Style Tendency in Fashion Design [J]. Science \& Technology Information, 2011(1): 279-280.

[4] Cheng Qi. Study of the Concept of Environmental Protection Applicating in the Course of Fashion Design [J]. Ecological Economy, 2014(2): 233-236. 
